\title{
EL ORIGEN DE LO POLÍTICO DENTRO DE LO IMPOLÍTICO ESPOSITEANO: COMENTARIO CLARIFICADOR DE LA POLÍTICA COMO TÉCNICA EN ROBERTO ESPOSITO
}

\author{
Miguel Lobos Zuzunaga \\ Instituto de Filosofía, Pontificia Universidad Católica de Valparaíso \\ Miguel.lz@hotmail.cl
}

\begin{abstract}
RESUMEN / ABSTRACT
Investigamos la crítica de la Italian Theory, desde Roberto Esposito, a la degeneración política presente en las concepciones críticas de la modernidad, entendida aquélla como una salida de lo político y como tecnificación, pretendiendo entonces otorgar una clarificación de estas reflexiones y de la propuesta de Esposito: identidad entre técnica y política. Con un trabajo hermenéutico-analítico, aclararemos qué mienta técnica en aquellos autores y en la reflexión espositeana. Derívase de este novedoso pensamiento una concepción técnica de lo político, y constituye un nuevo acceso para la pregunta por el hombre desde la técnica, desde una pura clave de actividad política.
\end{abstract}

Palabras clave: Italian theory, conflicto, origen de la política, degeneración política, técnica política.

\section{THE ORIGIN OF THE POLITICAL WITHIN THE ESPOSITEAN INPOLITICAL: CLARIFYING} COMMENTARY ON POLITICS AS A TECHNIQUE IN ROBERTO ESPOSITO

We investigate the answer of the Italian Theory, from Roberto Esposito, to the political degeneration proposed in the critical authors of modernity, understood as a way out from politics and as a technification. We'll provide a clarification of these critical thoughts and the proposal of Esposito: an identity between technology and politics. With an hermeneutic-analytical paper, we will clarify what is technology in those authors and in Esposito's thought. This contemporary endeavor allows to claim a technical conception of political reality, and constitutes a new access to the question about humankind through technology, from a pure political activity point of view.

KEYWORDS: Italian theory, conflict, origins of politics, political degeneration, political technology. 
“...quienes Zeus / destinó devanar desde la juventud hasta la vejez un ovillo / de dolorosas guerras, hasta que nos consumamos uno a uno".

Ilíada XIV, 85-87

\section{Introducción}

RA Lo que nos proponemos en lo siguiente es aclarar un elemento que pasa desapercibido en algunos textos de Esposito y cuya importancia no ha sido suficientemente sopesada en sus consecuencias. Precisamente, el tema de la expresión misma de lo político y su origen -en la distinción del par lo político y la política, en sus niveles ontológicos y ónticos-constituye, pensamos, un núcleo que permite funcionar como una entrada a las propuestas políticas de corte italiano contemporáneo y mostrar algunas relaciones filosóficas que se encuentran en este entramado.

Tal elemento es el de la relación entre técnica y política, que se anuncia determinadas veces en ciertos escritos de este pensador ${ }^{1}$, pero que en sus mismos contextos la situación queda oscurecida y no patentemente instituida, mucho menos investigada por su carácter aparentemente accidental. Intentaremos, entonces, abarcar esta relación para comprender el origen de la política en el marco de la filosofía impolítica ${ }^{2}$, tratada esta como la mirada despejada más reciente hacia el hecho mismo de la política. Se trata, entonces, de poder dar cuenta de esta relación que es de partida equívoca, equivocidad a partir de la cual articularemos este trabajo y que consiste principalmente en una determinada idea de la técnica concordante con una determinada idea del ser político, y que entenderemos fundamentalmente desde Arendt, Schmitt y Max Weber, frente a la propuesta de Roberto Esposito, la cual identifica, de una manera que nos proyecta a esclarecer en este artículo, técnica y política. Esto requiere una que otra idea introductora.

1 Puede verse, por ejemplo, que es un tema recurrente, mas periférico, al confrontar con: Esposito 2006, 22 y ss. y 74 y ss.; Esposito 2007, 90-94.

2 Evitando equívocos: "Que lo impolítico no comporta un debilitamiento o una caída del interés por la política sino, por lo contrario, una intensificación y radicalización de la política, es algo atestiguado sin posibilidad de equívoco no solamente por la obra sino también por la biografía de todos los autores que en él se reconocen, desde Hannah Arendt hasta Simone Weil, desde Hermann Broch hasta Georges Bataille, y últimamente, hasta René Char" (Esposito 2006, 11); “Tal como este libro trata de argumentar a través de 'sus' autores, para lo impolítico no existe una entidad, una fuerza, una potencia que pueda oponerse a la política desde el interior de su propio lenguaje. Pero tampoco desde afuera, pues ese 'exterior' no existe sino como proyección ideológica, mítica, autolegitimadora, de lo político mismo que ha llegado a la 'guerra civil' con su propio 'gemelo', lo antipolítico" (Esposito 2006, 13). 
En lo que concierne a estos dos elementos, técnica y política, tomamos las preocupaciones tempranas de Esposito en las categorías de la modernidad y su relación con el devenir político, nodo conceptual que recorreremos con dos lineamientos: una clarificación de lo que quiere significar que lo político sea en su origen técnico o no, deslizándonos por el entramado que abra la reflexión de Esposito en este punto y que muestre cómo sus conceptos y problematizaciones dan paso a una calificación técnica de la política. Apuntamos, entonces, no a una divagación sobre el ser de la técnica en general -por ser un espacio de discusión en sí mismo ${ }^{3}$ - sino a una pretensión más determinada, más radical, y más específica: proponemos investigar estos conceptos en el mismo hecho al cual mientan ambas perspectivas políticas fundamentalmente diferentes: la de los críticos a una política modernamente contaminada y la de la reflexión impolítica. Expondremos, en consecuencia, la perspectiva de los "críticos de la civilización" (Esposito 2006, 22) y posteriormente subrayaremos en oposición la propuesta espositeana, al entender lo político como la herida profunda de la pugna misma, y por esto, como esfuerzo ya técnico, en una caracterización heideggeriana que en su momento recordaremos.

\section{II}

\section{Esencialismo político y contaminación política}

La forma de presentar Hannah Arendt la situación que queremos resolver nos servirá a la manera de imagen en la que entran en juego los elementos a exponer en este apartado. Afirma Arendt en Sobre la revolución:

Para llegar a ella [la justificación de la lucha organizada] es preciso que exista la convicción de que las relaciones políticas no están sujetas, cuando se desarrollan normalmente, al imperio de la violencia, y tal convicción la encontramos por primera vez en la Grecia antigua, una vez que la polis griega, la ciudad-Estado, se definió a sí misma como un modo de vida basado exclusivamente en la persuasión y no en la violencia... Sin embargo, debido al hecho de que para el griego la vida política no se extendía... más allá de los muros de la polis, no se creyó necesario justificar el empleo de la violencia en la esfera de lo que hoy llamamos asuntos exteriores (Arendt 1988, 12).

Extendiendo esta idea, tenemos como un primer momento que, desde una perspectiva territorial casi geopolítica, la polis se instituye como cierto espacio en blanco, un momento de pureza política posibilitado solamente por la expulsión de la violencia, la guerra, hacia los puntos exteriores de la misma, hacia ese lugar (el intersticio político)

Sobre la técnica, por ejemplo, casos descollantes véase: Ortega y Gasset 1964, 317-371; Zubiri 1986, 323-61; Duque 2001; Heidegger 1994, 9-37. Volveremos sobre estas nociones ya clásicas más adelante. 
que en la unión violencia y no-política conecta guerreramente con los otros espacios políticos, reconociendo en sí misma un núcleo tras sus muros, el estado calmo en un flujo argumentativo (pensemos, por ejemplo, en las plazas y monumentos por los que se paseaba Sócrates, tan querido por Arendt) que es el lumen político, el lugar que se ha vaciado, digámoslo así, de muerte para dar lugar al phainómenon político. De alguna manera, algo similar encontramos en uno de los primeros registros políticos, más bien en su aspecto de forma de gobierno, precisamente en lo que sería el Discurso fúnebre de Pericles: "les llevamos la ventaja [a los espartanos] de que no nos angustiamos de antemano por las penurias futuras [la guerra], y, cuando nos toca enfrentarlas, no demostramos menos valor que ellos que viven en permanente fatiga" (Tucídides 6) ¿Podrá este acercamiento terrestre ser indicio de un particular status metafísico de la política desde el cual ésta pueda degenerarse? Creemos que sí; una polis, en conflicto, no sería, desde esta primigenia afirmación político-historiográfica, una polis adecuada; pero antes de abandonarnos a ello, veamos la cuestión desde el prisma de lo históricofilosófico, citando a Esposito:

¿No es exactamente éste el punto en el cual se cruzan las perspectivas de Weber, de Schmitt y de Arendt (menos impolítica), sino también de tantos “críticos de la civilización"? En un determinado momento, la política sale fuera de sí, traiciona su propia esencia y cae presa de la técnica (Esposito 2006, 22).

Para adentrarnos en este histórico supuesto devenir de la política, nos dirigimos al gran problema político de orígenes modernos, el de la representación entendida por Schmitt como el hacer visible y presente públicamente un ser imperceptible (el cuerpo de hombres), -y como factor determinante para la conformación de un Estado nación:

En la realidad de la vida política no hay un Estado que pueda renunciar a todos los elementos estructurales del principio de la identidad, como no lo hay que pueda renunciar a todos los elementos estructurales de la representación... Ambas posibilidades, identidad y representación, no se excluyen entre sí; no son más que puntos de orientación contrapuestos para la conformación concreta de la unidad política (Schmitt 1982, 206).

Tenemos aquí varios elementos que sopesar. Primero, que el ser imperceptible es, interpretando a Schmitt, un ser extra político, y que por tanto la conformación política (y de ahí la posibilidad de hablar de una unidad de Estado) depende de la situación del representar-Vertretung. Segundo, que la caída de la representación por otra estructura "pseudo" política de carácter privado y no civil, como la intervención puramente económica, conduce inevitablemente a una situación que es infrapolítica, cuyos rasgos no son por tanto nada políticos, sino culturales, económicos, serviles... la naturalidad política de la representación queda entonces emplazada por una fantasmagórica forma de política, una “mala" política. Algo así surgiría, por ejemplo, en el Leviatán, donde la representación no sería una cuestión natural para la vida política, una cuestión “existencial” (cf. Bialakowsky 2011, 291-292), sino una normatividad contractualista negativa, por así decir, para la seguridad de la nuda vida, una vida que no es política: la existencia del Estado presente para la protección de una vida apolítica: zoé. Escribe así: 
El Estado que naciera en el siglo XVII, llegando a afirmarse en toda el área del Continente europeo, es, en realidad, una obra humana y distinta de todos los tipos anteriores de unidad política. Se le puede considerar como el primer producto de la época técnica... En este tipo de Estado no solo se da ya el supuesto sociológico e histórico de la época técnica industrial siguiente, sino que él mismo es obra típica y aun prototípica de la nueva época técnica (Schmitt 2002, 33).

Agregando otro elemento degenerativo al Estado moderno, no tenemos que olvidar que en la política de Schmitt el elemento trascendente es su acompañante. No nos detendremos en profundidad en la forma teológica de su política que es el gran blanco de críticas impolíticas, y al respecto solo mencionaremos que para este autor "todos los conceptos centrales de la moderna teoría del Estado son conceptos teológicos secularizados. Lo cual es cierto no solo por razón de su evolución histórica, en cuanto fueron transferidos de la teología a la teoría del Estado... sino también por el reconocimiento de su estructura sistemática" (Schmitt 2009, 37), relacionándose con lo anterior en una analogía de representación de un valor trascendente (el Bien) y la representación política. Recogeremos lo que expone Esposito en Diez pensamientos acerca de la política:

... en la era de la Técnica al catolicismo le están asignados el monopolio y la defensa de la política en un mundo cada vez más despolitizado. Pero evidenciando en otros aspectos el carácter utópico de dicha defensa... Utópica como una isla en el océano de la despolitización moderna (Esposito 2012, 45; cursivas nuestras).

Algo "técnicamente" similar ocurre en Max Weber. Para Weber será suficiente plantearnos quién es el tipo de hombre que es político y en dónde se encuentra el poder. En esto queda propuesta no la salida de la violencia a un espacio guerrero como en Arendt, sino, curiosamente, la llegada casi competitiva a un espacio entronado del poder dentro del conjunto de hombres: la polis está en lo alto.

Estado es aquella comunidad humana que, dentro de un determinado territorio... reclama para sí el monopolio de la violencia física legítima... El Estado es la única fuente del "derecho" a la violencia. Política significará, pues, para nosotros, la aspiración a participar en el poder o a influir en la distribución del poder entre los distintos Estados o, dentro de un mismo Estado, entre los distintos grupos de hombres que lo componen... Quien hace política aspira al poder; al poder como medio para la consecución de otros fines... o al poder "por el poder", para gozar del sentimiento de prestigio que él confiere (Weber 1979, 83-84).

Luego de estas topográficas tentativas, podemos agregar para finalizar este apartado, la vida activa -y así, política- de Arendt. Es bastante aceptable su tesis que mostramos al comienzo si consideramos toda la importancia que tiene para la escritora del exilio el ser con otros; tanto es así no se es humano si no se está en la actividad con otro: "Solo la acción es prerrogativa exclusiva del hombre; ni una bestia ni un dios son capaces de ella y solo ésta depende por entero de la constante presencia de los demás" (Arendt 2009, 38). La condición humana fundamental sería algo semejante a una perenne y casi biológica compañía humana, mientras que la vida activa abocada a la política es 
por excelencia, digámoslo repetitivamente, la alta alianza para un propósito concreto, la acción y el discurso para la no violencia de la conducción del mundo, en una esfera política sellada en el bíos politikós ${ }^{4}$ que es la geométrica metáfora de lo que expone en Sobre la revolución. Sin diálogo, sin con-cordancia, sin el abandono del idiotismo, de lo propio, sin dejar el espacio a la acción común y sin capacitar a los hombres para dedicar su vida a una segunda existencia, abandonamos la esencia política a que se configure o disperse mágicamente o en manos de quien puede, sin más, despolitizar a discreción.

Ya ha aparecido subrepticiamente la forma de la técnica en la que consistiría una degeneración política que atraviesa a los autores anteriores; para ello pensamos que la fórmula heideggeriana, "en su primera parte", logra resumirla bastante bien. Y es que, como afirmábamos antes con Esposito, la política podría, pensada desde el intersticio y esencialismo político, salir de sí misma, aniquilarse habiendo sido emplazada por otra estructura anti política que no permite su acaecimiento propio en la masa de hombres. Esa es la técnica pensada desde Heidegger, una técnica muy particular que denomina Gestell: una estructura emplaza, provoca, oscurece este espacio puro de la política, sea introduciendo la disonancia de la herida en la polis, rasgando el hilo representativo, desviando la mirada de un orden trascendente o no llegando a un poder ubicado en algún punto de las relaciones; así resulta natural decir "la estructura de emplazamiento [Gestell] deforma el resplandecer y el prevalecer de la verdad" (Heidegger 1994, 29).

III

\section{La polis agónica}

¿Qué ocurre con esta idea de lo político? Es la caída, desde la perspectiva de Esposito, que padece una filosofía política, que como filosofía quiere fundar algo a lo que, esta vez en clave política, concurre tarde. La filosofía, dice Esposito, no puede pensar a la política "si no es en la forma de representación" (Esposito 2012, 32). En otras palabras, no es de extrañarnos que nos encontremos con que la filosofía política apele en variadas ocasiones a estados hipotéticos de salvajismo, de cesión de derechos, a locaciones de la política en lo alto o en el mito fundante del utopismo.

Es de esta manera que se pone en marcha el pensar impolítico que abre la región de lo político en donde se descubre su forma fundamental de ser radical, eso que las filosofías anteriores no pudieron ver, esto es, el conflicto inmanente como el factum primordial que mide y da forma a cualquier hacer que es así político. La herida está en nosotros.

Si este esfuerzo del pensar requiere otra mirada para poder alcanzar lo político, y si a su vez la política como conflicto inmanente es "la única realidad y toda la realidad...

$4 \quad$ Para una mayor profundización entre la escisión de vida y vida política en Arendt, vid. Quintana 2009. 
y solo la realidad" (Esposito 2012, 14), su origen que no está en un tópos hyper ouranós ni en un sistema axiológico (como la buena o mala política, o un bien supremo; el mal radical ya ha sido despachado por Arendt) se ubica en una entramada relación fundamental en cuyos momentos articuladores (no por ello armoniosos) se destaca la influencia potencial de uno hacia otro: el hombre y la polis, lo que impide pensar una esencialidad política que en su origen se vea violada, negada como no política por un factor de emplazamiento como puede serlo la técnica así simplemente, técnicamente, entendida: el origen que es ya esa pugna entre la fuerza humana y la que lo envuelve.

¿A dónde van a parar estas consideraciones tan fundamentales sobre lo político? Si no es el poder ascendente o descendente, si no es el sector de élite, si no es el contrato hipotético o a futuro, la política se encuentra en la propia vida (cf. Esposito 2009, 2123). ¿Cómo puede ser esto mismo técnica? Para recalcar la oposición a los críticos de la civilización, leamos al mismo Esposito:

...nunca ha existido una pólis entendida como un cosmos unitario posteriormente quebrado. Así como nunca ha existido un orden natural después violado, extirpado y destruido por la violencia de la técnica. Por el contrario, desde el comienzo, las nómoi de la pólis entraron recíprocamente en conflicto, así como desde siempre la naturaleza se presenta "desnaturalizada" por y en la lógica suplementaria del artificio... En contra de ello, o mejor dicho fuera de ello, lo impolítico reconoce la perfecta cooriginariedad de técnica y política, y reconoce que no existe una práxis cualitativamente distinta de la téchne y precedente a ella, a diferencia de cuanto nos ha enseñado una larga tradición... Ello significa que la técnica no constituye el fin, sino el origen de la política (Esposito 2006, 22-23).

Se revela bajo este hilo argumentativo que la disonancia ad intra los muros de la polis -para continuar con la metáfora topográfica- con el hombre que emerge en esta trama de potencias en juego es la batalla sin fin de la política. Afirma el autor: “... [es] el corazón desgarrado que late en la extrema discordia. Si es imposible poner fin a la batalla, solo queda fijarla, como una contradicción insuperable, en nuestro interior. Y encomendarla así en las manos de Amor" (El origen 18). No una buena política: una política, un ser político, y una polis en pro del vivir y en pro de este fuerza que irrumpe en la polis: estamos aquí en el nacimiento de lo que será conocida como la división futura entre biopolítica -a la espositeana - y tanatopolítica.

La política, el hombre, la técnica, podemos verla en la continuación del estudio de Heidegger al respecto. La técnica cooriginaria a la política muestra el lado que no es el emplazamiento, como una forma práctica de suceder la técnica, sino el ser más propio de la misma, el hacer técnica de la técnica, su verdad que es la del hombre en la conquista a la que es llamado en la polis:

Solo el otorgar aporta al hombre aquella participación en el salir lo oculto a la luz que es la que necesita (y usa) el acaecimiento propio del desocultamiento. En tanto que necesitado (y usado) de este modo, el hombre está asignado como propio al acaecimiento propio de la verdad... Lo que destina de este o de aquel modo al hacer salir lo oculto es, como tal, lo que salva. Porque este que salva hace que el hombre mire e ingrese en la suprema dignidad de su esencia. La pregunta 
por la técnica es la pregunta por la constelación... en la que acaece de un modo propicio lo esenciante de la verdad... aquel salir oculto que trae-ahí-delante la verdad, llevándola al esplendor de lo que luce (Heidegger 1994, 33-36).

Es así que la polis se instituye agónicamente; el espacio en el cual el hombre emerge y hace vida, se involucra en las fuerzas de la polis y en la suya propia, alrededor de la cual su estancia va adquiriendo consistencia, su potencia se pone en dinamismo con la de los otros de manera tal que política y vida cumplen la forma del munus, de la obra, del oficio, de la tarea y función humana primordial, que bien puede ser enriquecida por el "don-a-dar" (Esposito 2007, 30), el regalo: una biopolítica afirmativa. Por el contrario, puede ser inhibida esta fuerza que se trae a ella y al mundo a la luz, como “apertura originaria” (Esposito 2007, 49), sacrificándola mediante su negación o por el residuo de la exclusividad del poder en una comprensión esencialista de la política. En este sentido es que la actividad técnica no se diferencia de la actividad política, pues es el mismo hombre en su comunidad quien se desenvuelve, y hace salir de lo oculto su vida y el mundo en sus manifestaciones en la red conflictiva de fuerzas de la que es parte. La estructura de emplazamiento que chocaba con la Política, ha sido cambiada por las potencias de unos encontrada entre las de los otros.

\section{Conclusión}

Bajo el alero de la exclusión conflictiva y guerrera posibilitadora del surgimiento de la polis, y así del ser político, se esconde el germen que frente a viento y marea logra dar, remedando la pluma de Heidegger, frutos en el éter. Con esto queremos decir que, si seguimos los planteamientos de Esposito, aun toda la tradición de la filosofía política y todas la teorías del Estado, con los calificativos que queramos (utópicos, míticos, teológicos, contractualistas, organicistas, etc.), incluyendo en esto las perspectivas de los autores trabajados aquí, se hizo factualmente necesario recuperar todo un subsuelo pasado por alto -con notables excepciones, como Simone Weil (cf. Esposito 2006, 41)- desde el cual es posible pensar la política ya no como fenómeno agregado, como privilegio, como un posible llegar a existir con la condición de la visibilidad representativa de Schmitt, sino como forma misma del hombre. Es de esta manera que la técnica política entendida desde Arendt, Schmitt y Weber como una degeneración política tiene coherencia si se piensa bajo los supuestos que sus teorías implican, esto es, una concepción de política que, aunque discutida, supuesta: una idea de política que se ha afirmado a sí misma y que, a su vez y por lo mismo, una salida de ella implica su tecnificación en el reconocido sentido negativo apuntado por Heidegger. No es necesario llegar más lejos para darnos cuenta de que de lo que se trataría la respuesta contemporánea italiana es recalcar que esta técnica política no es más que juzgar a posteriori una cultura política por sus efectos negativos. No obstante, en Esposito, si se ha de recuperar este factum propio de la política como una herida fundamental, como el conflicto o entrecruzamiento de bíos -dando así Esposito con la esencia de la técnica sin más, que recae de cajón en el producere mismo del sujeto y su proyecto-, entonces no hay degeneración posible 
de una supuesta esfera que tiene dentro de sí algo como la política por excelencia, y en otras palabras no es hacedero un desplazamiento de la misma. Por lo tanto, si no hay vuelta a un origen, si no es posible una etérea "homeostasis natural" (Zizek 2003, 28), pensar la política en estrecha relación con la técnica no tiene en apariencia nada dificultoso sino que muy por el contrario, es el paso que cruzan las categorías de lo impolítico de Esposito y que esperamos haber mostrado.

Más aún, si lo pensamos con los caracteres que le atribuye Heidegger a la técnica como la forma de traer delante -pro-ductum-, de establecer e instituir (cf. Esposito 2012, 157-158), como puede serlo la polis en un caso ${ }^{5}$ y la institución del mismo sujeto sobre el fondo de la comunidad política, la misma fuerza de la vida que emerge y así va configurándose, afirmándose, perfilándose, en su circunstancia y propio presentarse como un bíos político - sea esto tautología o no-, entonces logramos entender la íntima relación entre técnica y política que establece y permite Esposito.

Como último punto, es necesario destacar el aporte subrepticio que esta temprana perspectiva supone en las concepciones de política y técnica en la dimensión general del problema del hombre. En el primer caso, la tesis propuesta por el Esposito de estos estudios es fuerte y clara dentro de este repensar una ontología política que sale cada vez de sí misma, una especie de no-ontología que, al menos en este límite de los escritos de Esposito, no deja de suscitar la pregunta de si nos encontramos o no frente a un estructuralismo de un corte barroco, rizado el rizo. No obstante -y esto es lo que sobre todo permite otear estas tempranas reflexiones políticas de nuestro tiempo-, en el segundo caso nos encontramos con una nueva inflexión de lo técnico como origen de una pregunta actual y "del fin de la metafísica” de la que fuera entonces la psicología racional y que no ha dejado de dar frutos interesantes; tomemos por caso la técnica de Bergson comprendida como la creación adaptada no dispersa del homo faber que da cuerpo a su filosofía natural de la evolución creadora (cf. Bergson 1963, 552-560), y Zubiri y la técnica como síntesis del hacer y saber fundado sobre la estructura de saber y realidad (cf. Zubiri 1986, 323-341). Es decir, en Esposito -y he aquí lo relevante de nuestra exposición-nos encontramos ante el intento de posibilitar un retorno abierto de lo político-impolítico aquí- y que en su patencia reclama para sí su realidad primigenia: hombre, técnica, política; la herida que abre al hombre entre sus congéneres un horizonte que no puede más que hacerse y devenir. Esto es: es la existencia quien guarda la esencia de la técnica y ésta se manifiesta en el político primigenio habitar de aquélla.

\section{Referencias bibliográficas}

Arendt, Hannah (2009), La condición humana. Trad. Ramón Gil. Buenos Aires: Paidós. Impreso.

$5 \quad$ No olvidar que para el Heidegger de 1936 una forma de obrar la verdad se encuentra en la institución de ciudades (Heidegger 2010, 45), instituir o fundar [setzen] que será corregido cuando hable, en vez, de un poner en obra [bringen] (cf. Heidegger 2003). 
(1988), Sobre la revolución. Trad. Pedro Bravo. Madrid: Alianza. Impreso.

Bergson, Henri (1963), Obras escogidas. Trad. José Miguez. México: Aguilar.

Bialakowsky, Guillermo (2011), “Tiempo y representación. La crítica impolítica italiana al pensamiento de Carl Schmitt", Instantes y azares: escrituras nietzscheanas 9: 289-300. Digital.

Duque, Félix (2006), ¿Hacia la paz perpetua o hacia el terrorismo perpetuo? Madrid: Pensamiento. Impreso.

Esposito, Roberto (2006), Categorías de lo impolitico. Trad. Roberto Raschella. Buenos Aires: Katz. Digital.

(2009), Comunidad, inmunidad y biopolitica. Madrid: Herder. Impreso.

(2007), Communitas: Origen y destino de la comunidad. Buenos Aires:

Amorrortu. Impreso.

(2012), Diez pensamientos acerca de la politica. Buenos Aires: FCE. Impreso.

(1999), El origen de la política ¿Hannah Arendt o Simone Weil? Trad. Rosa Rius. Barcelona: Paidós. Impreso.

Guzzini, Stefano (2015), “El poder en Max Weber”, Relaciones Internacionales 30: 97-115. Digital.

Heidegger, Martin (1994), Conferencias y artículos. Barcelona: Odós. Impreso.

Homero (1982), Ilíada. Trad. E. Crespo. Madrid: Gredos. Impreso.

Ortega y Gasset, José (1964), Obras Completas v. 5. Madrid: Revista de Occidente. Impreso.

Quintana, Laura (2009), "Vida y política en el pensamiento de Hanna Arendt", Revista de Ciencia Política 29: 185-200. Digital.

Schmitt, Carl (2002), El Leviathan en la teoría del estado de Tomás Hobbes. Trad. Javier Conde. Buenos Aires: Struthart. Impreso.

(2009), Teología Politica. Trad. Javier Conde y Jorge Navarro. Madrid: Trotta. Impreso.

(1982), Teoría de la constitución. Trad. F. Ayala. Madrid: Alianza. Impreso.

Tucídides, El Discurso Fúnebre de Pericles. Centro de Estudios Públicos. Web. 20.feb.2017: https://www.cepchile.cl/cep/site/artic/20160303/asocfile/ 20160303184915/rev11_tucidides.pdf

Weber, Max (1979), El político y el científico. Trad. Francisco Rubio. Madrid: Alianza. Impreso.

Zizek, Slavoj (2003), El sublime objeto de la ideología. Buenos Aires: Siglo XXI. Impreso.

Zubiri, Xavier (1986), Sobre el hombre. Madrid: Alianza. Impreso. 